\title{
Magnitude of $G_{1}$ reward and the frustration effect in a between subjects design
}

\author{
R. A. KRIPPNER ${ }^{1}$, UNIVERSITY OF SOUTH DAKOTA, R. C. ENDSLEY, UNIVERSITY OF GEORGIA \\ R. S. TACKER, UNIVERSITY OF SOUTH DAKOTA
}

The Peckham-Amsel (1964) demonstration of a positive relationship between magnitude of reward and the strength of the frustration effect (FE) was reexamined using a between-Ss design. Confirming the Peckham-Amsel findings, Ss under the large reward condition ran slower in the second alley $\left(\mathrm{A}_{2}\right)$ during acquisition trials and faster following nonreward test trials than did $S$ s under the small reward condition.

Amsel's theoretical treatment of frustrative nonreward (1962) assumes that the strength of the frustration effect (FE) is positively related to the magnitude of the fractional anticipatory reward response $\left(r_{r}\right)$. Since the strength of $r_{r}$ is assumed to be a positive function of the magnitude of reward (Spence, 1956), FE should also be a positive function of reward magnitude. Peckham \& Amsel (1964) confirmed this prediction using the typical double runway apparatus and a design in which Ss were trained under both large and small reward conditions in two different first runways (i.e., a within Ss design). The purpose of the present study was to determine if the hypothesized relationship between reward magnitude and FE would be demonstrated when the second runway performance of Ss trained in the first runway under a large reward condition was compared with that of Ss trained in the first runway under a small reward condition (i.e., a between Ss design).

Method

The Ss were 12 experimentally naive male LongEvans hooded rats, ranging in age from 100-110 days at the start of the experiment.

The apparatus was an L-shaped double runway with a 12 in. start box $\left(S_{1}\right)$ and two 12 in. goal boxes $\left(G_{1}, G_{2}\right)$. The first and second alleys $\left(A_{1}, A_{2}\right)$ were 48 in. and 60 in., respectively. The start box, goal boxes, and alleys were $5 \mathrm{in.high}$ and $4 \mathrm{in}$. wide throughout. The first runway of the apparatus $\left(S_{1}-A_{1}-G_{1}\right)$ was painted white, and the second runway was flat black. Glass caster cups were placed at the end of $G_{1}$ and $G_{2}$ to serve as food dishes.

Guillotine start doors were located between $S_{1}$ and $A_{1}$ and between $G_{1}$ and $A_{2}$; guillotine retrace doors were located between $A_{1}$ and $G_{1}$ and between $A_{2}$ and $G_{2}$. Raising the door between $G_{1}$ and $A_{2}$ activated a .01 sec Hunter Klockounter which stopped when $S$ interrupted an infrared photocell beam located 16 in. from $\mathrm{G}_{1}$ (start time). Interruption of the same photocell beam activated another .01 sec Klockounter, which was stopped when a second photobeam was interrupted 40 in. from the first beam (running time).
At the start of the experiment, the 12 Ss were randomly assigned to two groups: Group 5-1 and Group 10-1. The group numbers represented the number of $45 \mathrm{mg}$ Noyes pellets $\mathrm{Ss}$ would receive in $\mathrm{G}_{1}$ and $G_{2}$, respectively, on any rewarded trial. For example, $S s$ in Group 5-1 would receive five pellets in $G_{1}$ and one pellet in $G_{2}$ per trial. During the first 10 days of pretraining, as well as throughout the remainder of the experiment, Ss were maintained on a $23 \mathrm{~h}$ food deprivation schedule. Water was available ad lib. On each day of pretraining, Ss were handled for $5 \mathrm{~min}$ and were fed in $G_{1}$ and $G_{2}$ the number of food pellets appropriate to their group designation.

An acquisition trial began by placing $S$ into $S_{1}$. After $S$ had oriented toward the door for $2 \mathrm{sec}$, the door was removed and $S$ was allowed to traverse $A_{1}$ and enter $G_{1}$. When $S$ had eaten the pellets and oriented for $2 \mathrm{sec}$ toward the door between $G_{1}$ and $A_{2}$, this door was removed and $S$ was allowed to traverse $A_{2}$ and $\mathrm{G}_{2}$. Immediately after eating the pellet in $\mathrm{G}_{2}, \mathrm{~S}$ was removed to the carrying cage.

The procedure for test trials was the same as for acquisition trials except that nonreward was introduced in $\mathrm{G}_{1}$ on half of the test trials. During each block of four test trials, both groups received $G_{1}$ reward (R) or nonreward (N) trials according to the following repeating sequences: RNRN/RNNR/NRNR/ NRRN.

The experiment consisted of 72 acquisition trials and 72 test trials. Each $S$ ran four trials per day except on the first, second, and third days of training when the number of trials per $S$ was one, one, and two trials per day, respectively. The intertrial interval for each $\mathrm{S}$ was approximately $7 \mathrm{~min}$ within each session. All Ss were run in squads composed of one $S$ from each treatment group. Throughout the experiment, the six squads and Ss within squads were tested in a counterbalanced order.

\section{Results and Discussion}

The start and running time data were reciprocalized (1/sec) and treated as start and running speeds. Comparison of the start speeds of Groups 5-1 and 10-1 is shown in Fig. 1.

A two factor analysis of variance with repeated measures on one factor was performed on the acquisition start speed data. The analysis yielded a significant Trial Blocks effect $(F=3.2$, df $=8 / 80, p<.01$ ), but neither the Groups effect nor the Groups by Trial Blocks interaction effect was significant. While the 

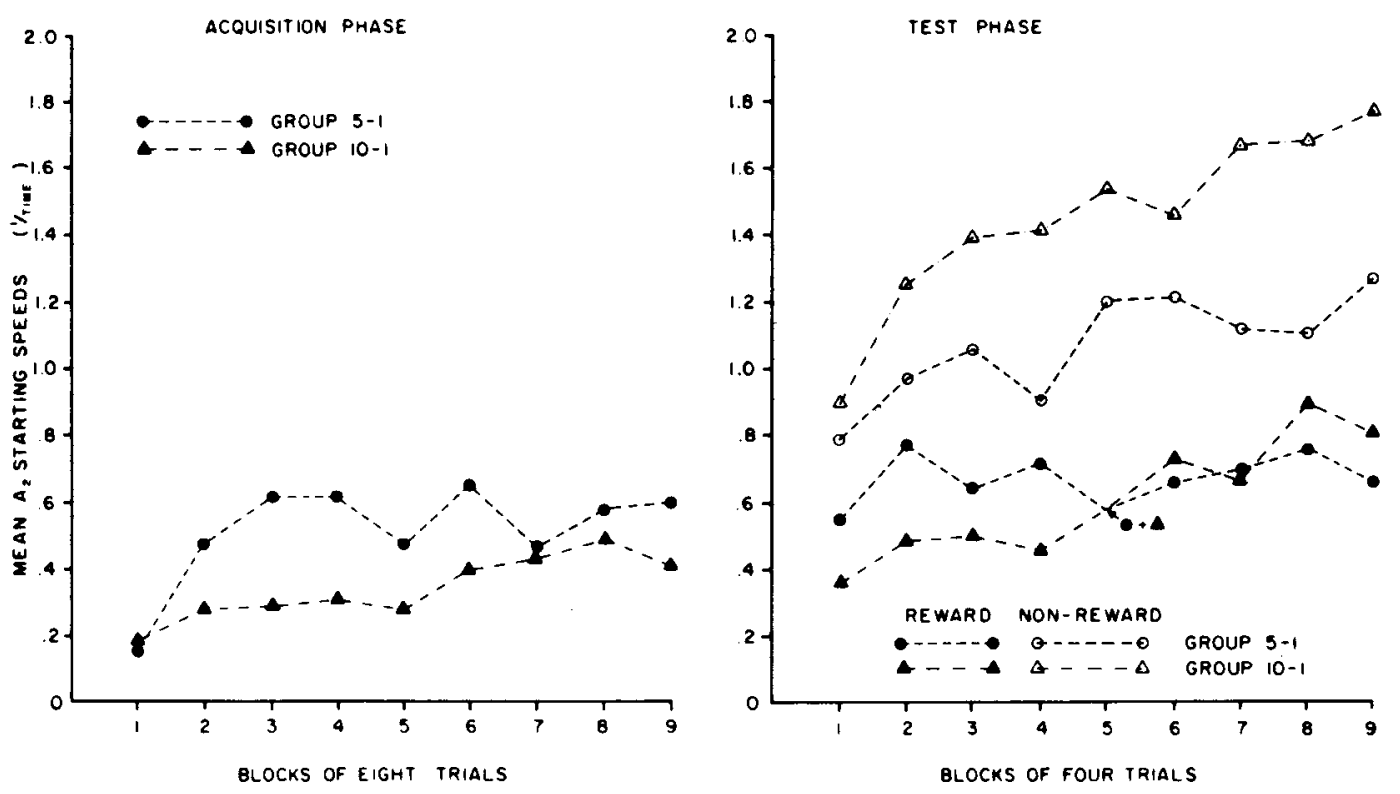

Fig. 1. Mean $A_{2}$ starting speeds as a function of trial blocks.

Groups effect was nonsignificant, inspection of Fig. 1 indicates that Group 5-1 started faster than Group 10-1 on all but the first block of trials.

A three factor analysis of variance with repeated measures on two factors was performed on the test trial starting speeds, with Groups, Reward Conditions (reward-nonreward), and Trial Blocks as the main effects. The main effects of Trials $(F=2.9, \mathrm{df}=8 / 80$, $p<.01)$, Reward Conditions $(F=62.5, d f=1 / 10, p<.01)$, and the Reward Conditions by Groups interaction ( $F$ $=8.5, \mathrm{df}=1 / 10, \mathrm{p}<.05)$ were the only significant effects. Inspection of Fig. 1 indicated that the significant Reward Conditions by Groups interaction resulted from the fact that $S s$ in Group 10-1 started faster than Ss in Group 5-1 following $G_{1}$ nonreward but not following $G_{1}$ reward. This interaction pattern is exactly what is predicted by the hypothesis that FE is a positive function of $G_{1}$ reward magnitude.

The acquisition and test running speed data were highly similar to the start speed data portrayed in Fig. 1. However, analysis of variance yielded no significant Groups effect during acquisition nor the predicted Reward Conditions by Groups interaction during test trials. It is speculated that the failure to obtain the latter interaction effect may have resulted, in part, from measuring the $S^{\prime} s$ running time too near $G_{2}$ (i.e., to within 4 in. of the entrance to $G_{2}$ ). It is possible that measuring S's locomoting behavtor near $G_{2}$ may have resulted in including $S$ 's tendency to slow down on approaching the $G_{2}$ foodcup in the measure of running time.

Despite the nonsignificant Groups effect for both start and running speeds during acquisition, the consistently faster speeds for Group 5-1 on all but the first block of trials is notable in light of the same pattern of results found by Peckham and Amsel. Assuming that large reward magnitude in $G_{1}$ does, in fact, depress $A_{2}$ speeds as compared with small $G_{1}$ rewards, the explanation for such a relationship remains to be explored. One possibility is that Ss receiving large $G_{1}$ rewards have a strong tendency to remain in or return to $G_{1}$ rather than approach $\mathrm{G}_{2}$, as compared with $\mathrm{Ss}$ receiving small $\mathrm{G}_{1}$ reward. Such tendencies might then be expected to compete with start and running behavior, at least early in training.

\section{References}

AMSEL, A. Frustrative nonreward in partial reinforcement and discrimination learning: Some recent history and a theoretical extension. Psychol Rev., 1962, 69, 306-328.

PECKHAM, R. H. Jr., \& AMSEL, A. Magnitude of reward and the frustration effect in a within-subjects design. Psychon. Sci, 1964, 1, 285-286.

SPENCE, K. W. Behavior theory and conditioning. New Haven: Yale Univer. Press, 1956.

\section{Notes}

1. This research was carried out during the tenure of a National Defense Education Act Title IV Pre-doctoral Fellowship. This paper is based upon a Masters Thesis, University of South Dakota, January 1967. 